\title{
Adsorption of Lead using Jackfruit Peel Activated Carbon
}

\section{Nor Azalina Rosli ${ }^{1, a}$, Mohd. Hafiz Zawawi ${ }^{2}$, Rosmina A. Bustami ${ }^{3}$,} Fadzren Hipni ${ }^{4}$ and Mohamad Anuar Kamruddin ${ }^{5}$

\author{
${ }^{1,3,4}$ Dept. of Civil Engineering, Faculty of Engineering, Universiti Malaysia Sarawak (UNIMAS) \\ ${ }^{2}$ Dept. of Civil Engineering, College of Engineering, Universiti Tenaga Nasional (UNITEN) \\ ${ }^{2,5}$ School of Civil Engineering, Campus of Engineering, Universiti Sains Malaysia (USM) \\ arnazalina@feng.unimas.my
}

Keywords: adsorption, activated carbon, wastewater

\begin{abstract}
Adsorption using activated carbon that decomposed from agricultural waste has been proven to be effective in removing heavy metals in wastewater. This study was carried out to investigate the adsorption of heavy metals wastewater (Lead) using activated carbon that synthesized from the fruit waste which is jackfruit peel. The efficiency of jackfruit peel activated carbon in removing lead from wastewater has been compared to the commercial activated carbon. Result shows that the commercial activated carbon gave better result as compared to jackfruit peel activated carbon ( $98 \%$ of lead removal for commercial activated carbon and $80 \%$ of lead removal for jackfruit peel activated carbon). This can be explained from the characteristics of the activated carbon where the commercial activated carbon has a very well develop pores structures in contrast to jackfruit peel activated carbon. In term of isotherm and kinetic study, the Freundlich isotherm model is better fitted in equilibrium adsorption isotherm for jackfruit peel activated carbon and it is favorable adsorption condition. For commercial activated carbon, the Langmuir isotherm is better fitted to the adsorption of lead and monolayer adsorption capacity was found. The experimental data fitted very well the pseudo second order in kinetic model for both activated carbon where the adsorption controlled by chemisorptions.
\end{abstract}

\section{Introduction}

The growth of industrial technology results in greater pollution towards the environment especially wastewater discharge containing high concentration of heavy metal. Lead is one of heavy metal with specific toxicity and cumulative effects. Lead is normally used in storage batteries, insecticides, plastic water pipes, food, beverages, ointments and medicinal concoctions for flavoring and sweetening [1]. However due to high cost of treatment, wastewater are not being well treated before it is released into water bodies. According to [2], lead can affects the human health by causing damage to liver, kidney and reduction in hemoglobin formation, mental retardation, infertility and abnormalities in pregnancy and death.

Treatments such precipitation, coagulation and flocculation, iron exchange, reverse osmosis [3] and biological treatment [4] have been proposed to remove heavy metals from wastewater. Yet, all of these methods suffered with one another limitation and none of these were successful in removing heavy metal completely. Activated carbon adsorption has been proven to be superior compared to other techniques in terms of its simplicity of design, high efficiency and ease of operation. It is recognized as the most efficient and promising fundamental approach in the waste water treatment processes [5]. Nevertheless according to [6], the high cost of activated carbon production and the limited supply became the main concern. In order to solve this problem, many researchers come up with an alternative adsorbent derived from agricultural waste i.e. pinecone, rice husks and peanut hulls which in generally efficient in the adsorption as the commercial activated carbon. 
Agricultural waste has a significant composition in the waste landfilled in Malaysia, which is an agro based country. Thus, utilization of agricultural waste as the raw material for activated carbon can reduce the amount of waste landfilled and as a result prolong the lifespan of landfill. According to data reported by the Ministry of Agricultural and Agro- Based Industry Malaysia, the annual production of jackfruit in 2011 was projected at 56,631 MT, translating to approximately 33,979 MT of jackfruit peel as by products [7]. In this study, jackfruit peel is chosen as the precursor in the production of activated carbon due to its availability all year round. The study is involving the evaluation and comparison of the efficiency of adsorbent derived from jackfruit peels for removal of lead with the commercial activated carbon.

\section{Materials and Method}

Jackfruit peel preparation. Jackfruit peels (precursor) were collected from Kampung Niup at Kota Samarahan, Sarawak and around Kuching City and prepared i.e. cut into small pieces, washed with distilled water, dried in oven with temperature $105^{\circ} \mathrm{C}$ for 24 hours and grinded into granular sizes. Then the precursor were impregnated with chemical agents (85\% Ortho-phosphoric acid) before the carbonization process take place by heating the impregnated precursor by ramping the temperature from room temperature to $800^{\circ} \mathrm{C}$ with heating rate $10^{\circ} \mathrm{C} / \mathrm{min}$ for 3 hours via nitrogen gas.

Commercial activated carbon. The commercial activated carbon was supplied by Bravo Green Sdn. Bhd. The adsorbent were used directly without any further grinding and sieving.

Laboratory Activities. Both jackfruit peel activated carbon (JPAC) and commercial activated carbon (CAC) were analyzed to determine their physical and chemical characteristics i.e. surface morphology, surface structure and pore arrangement were obtained from the Scanning Electron Microscopy (SEM) experiment, and the elemental analysis was found via Energy-dispersive X-ray spectroscopy (EDX) analysis.

Batch and kinetic adsorption test. The experiment was conducted by placing the wastewater samples into $250 \mathrm{~mL}$ Erlenmeyer flask which was kept on orbital shaker for period of time. The adsorption performance i.e. effect of initial lead concentration was studied by varying the initial lead concentration (3ppm, 5ppm, 10ppm, 20ppm and 50ppm), effect of contact time was determined by differing the contact time and effect of adsorbent dosage was examined by shifting the adsorbent dosage (500mg, 1000mg, 1500mg, 3000mg and 5000mg).Treated samples were analyzed using Atomic Adsorption Spectroscopy (AAS).

\section{Results and Discussion}

Effect of initial lead concentration. The experimental results of adsorption of lead on the activated carbon (JPAC and CAC) at various initial concentrations (3ppm, 5ppm, 10ppm, 20ppm and 50ppm) are shown in Figure 1. It reveals that the percent adsorption increase with the increase in initial lead concentration as well as the amount of dye adsorbed per unit mass of carbon increased with increase in initial lead concentration. However if the amount of adsorbent used is limited we will get the opposite trend of graph where the graph will decreased as the initial dye concentration is increased. Nevertheless the uptake rate of adsorbate is increasing until the adsorbent reached the endpoint. The percentage removal of lead using JPAC increased from $47 \%$ to $80 \%$ proportionally with the increase of initial lead concentration. Similar result obtained for CAC where the percentage removal increases from $56 \%$ to $89 \%$. It means that the adsorption is highly dependent on the initial concentration of lead. This is because higher initial concentrations lead to an increase in the affinity of the Lead ions towards the active sites. Moreover, this can be explained by the fact that more adsorption sites were being covered as the metal ions concentration increases. 


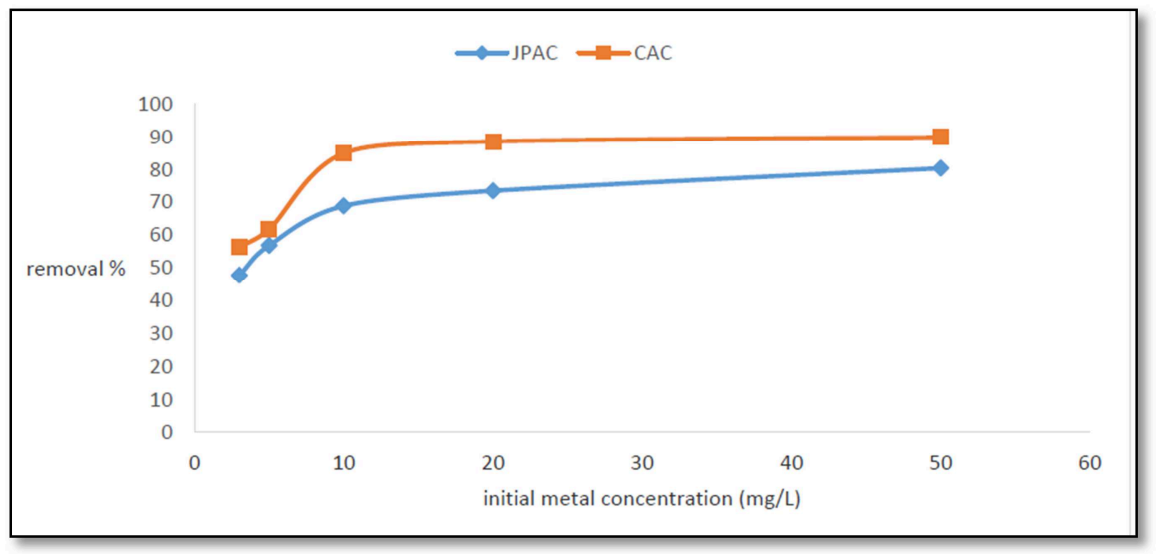

Figure 1: Initial metal concentration against removal percentage for Jackfruit Peel Activated Carbon and Commercial Activated Carbon (Contact Time; $24 \mathrm{hr}$, Adsorbent dosage; $1500 \mathrm{mg} / \mathrm{L}$ )

Effect of adsorbent dosage. The adsorption of the lead on adsorbent is studied by varying the adsorbent (JPAC and CAC) concentration (500mg, 1000mg, 1500mg, 3000mg and 5000mg) (refer to Figure 2). The result shows that the percentage of adsorption increases with increase in the adsorbent concentration. For $500 \mathrm{mg}$ of JPAC used, the percentage removal is $37.49 \%$ and the percentage of removal increase up to $88.4 \%$ when $5000 \mathrm{mg}$ JPAC was added. For CAC, it gives a similar trend as JPAC. The removal percentage increase when higher adsorbent dosage was used. This is due to the increase the adsorbent ratio and availability of more adsorption site.

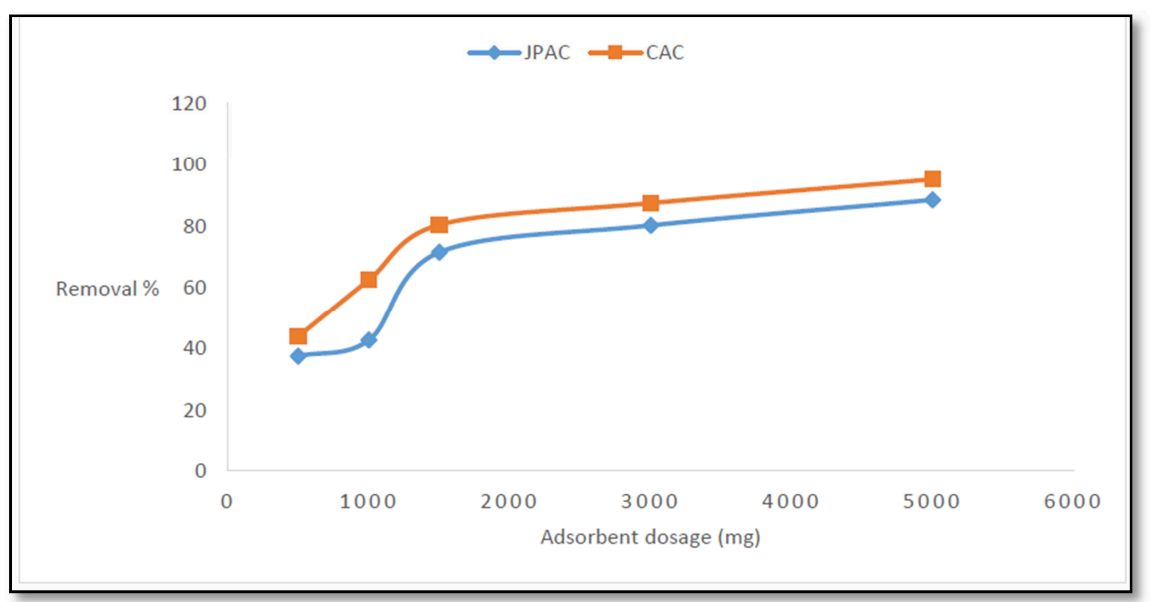

Figure 2: Adsorbent dosage against removal percentage for Jackfruit Peel Activated Carbon and Commercial Activated Carbon (Contact Time; 24 hr, Initial concentration; 5 ppm)

Effect of contact time. The effect of contact time on the adsorption process was studied at different time interval (10 min, $20 \mathrm{~min}, 30 \mathrm{~min}, 40 \mathrm{~min}, 50 \mathrm{~min}, 1 \mathrm{hr}, 2 \mathrm{hr}, 3 \mathrm{hr}, 4 \mathrm{hr}, 5 \mathrm{hr}, 23 \mathrm{hr}$, and $24 \mathrm{hr}$ ). The result obtained in Figure 3 shows that the percentage removal is rapidly increased from the first hour of adsorption for both JPAC and CAC. The increasing trend was due to the large number of vacant surface site are available for adsorption at early stage of adsorption. As the contact time increase, more pollutant attached to the surface of activated carbon until after some time the pores are fully occupied and reach an equilibrium point where the transfer process of lead molecules from bulk to the liquid to the external surface of activated carbon stopped. 


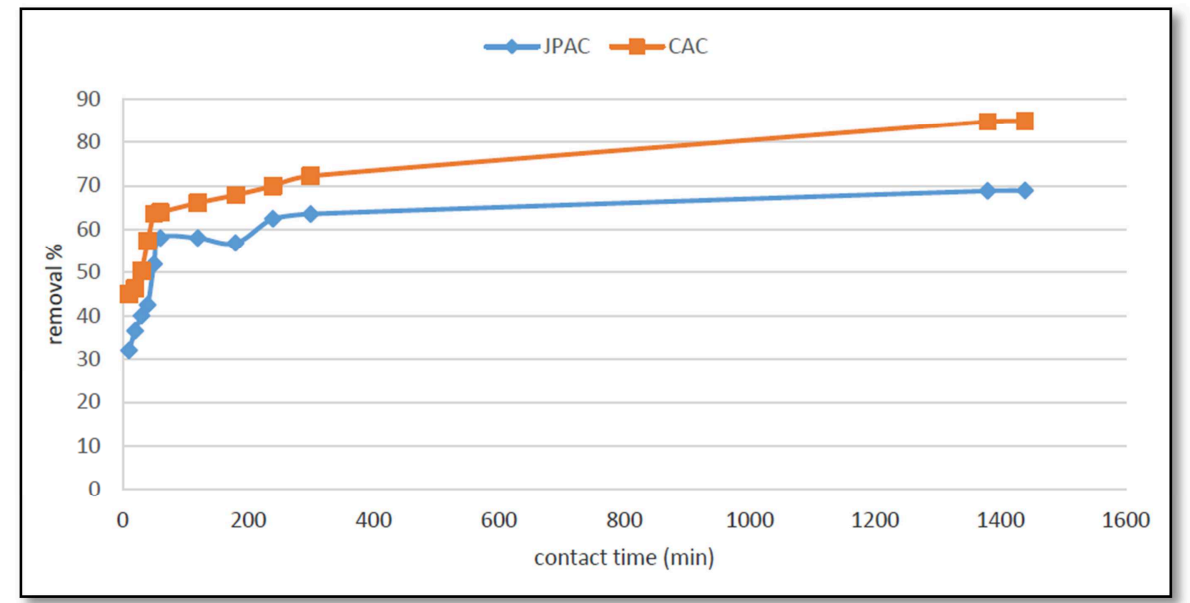

Figure 3: Contact time against removal percentage for Jackfruit Peel Activated Carbon and Commercial Activated Carbon (Initial metal concentration; $10 \mathrm{mg} / \mathrm{L}$, Adsorbent dosage; 1500 $\mathrm{mg} / \mathrm{L})$

Efficiency of JPAC and CAC. By referring to the adsorption performance that obtained, the commercial activated carbon has higher removal percentage compared to the jackfruit peel activated. This situation can be explained by the characteristics of JPAC and CAC. Based on the surface morphology analysis (refer Figure 4) it is clearly shown the surface morphology of CAC (Figure 4.b) is more porous and the pore structures are well developed compared to JPAC (Figure 4.a). Besides the CAC has higher surface area and pore volume which is $2587.798 \mathrm{~m}^{2} / \mathrm{g}$ and 0.77 $\mathrm{cm}^{3} / \mathrm{g}$ compared to JPAC which is $106.839 \mathrm{~m}^{2} / \mathrm{g}$ and $0.18 \mathrm{~cm}^{3} / \mathrm{g}$. In addition after batch experiment, both CAC and JPAC were examined to study the lead uptake onto the activated carbon. The result shows that more lead was adsorbed onto CAC that JPAC. From EDX result, it shows that there was $6.56 \%$ lead element exists in CAC and $2.11 \%$ of lead element present in JPAC after batch experiment.

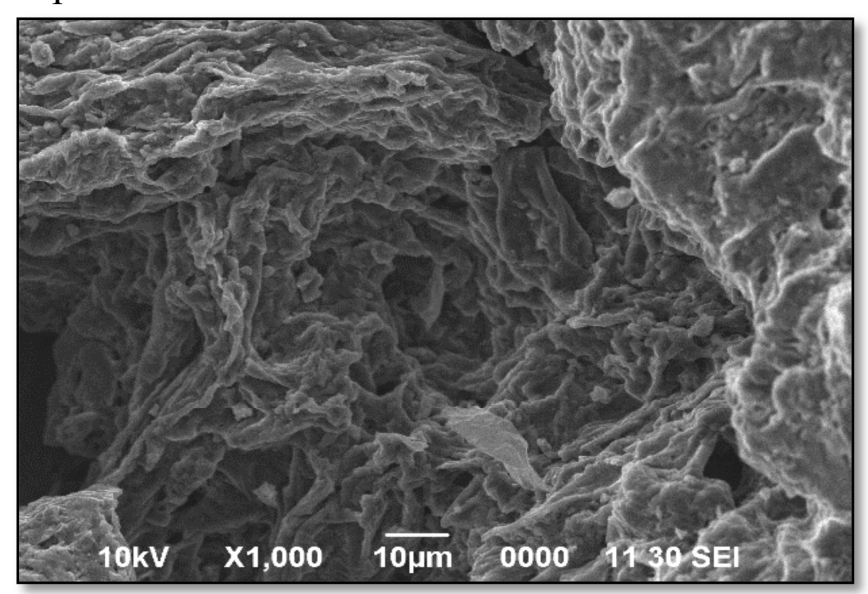

(a)

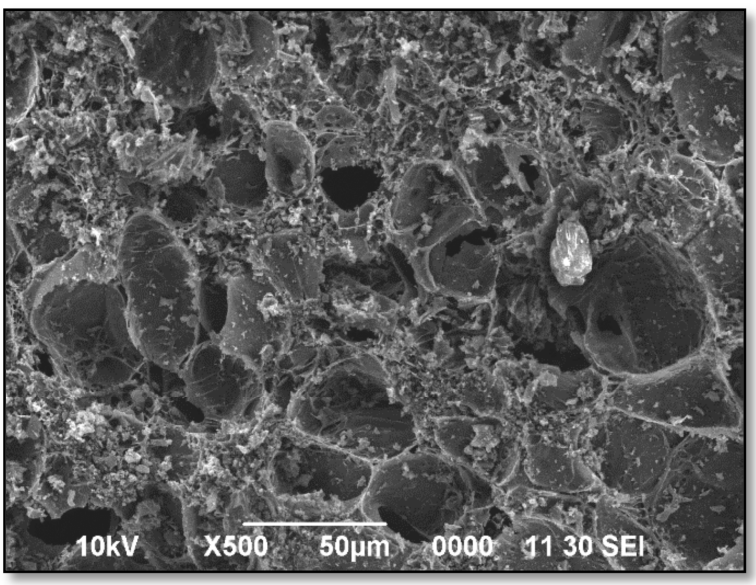

(b)

Figure 4: Surface morphology of (a) JPAC (b) CAC.

Adsorption Isotherm. Basically the adsorption isotherm was conducted to describe how the solutes interact with adsorbent and is critical in optimizing the use of adsorbents. The linear forms of two equations (Langmuir and Freundlich isotherms) were applied to fit the equilibrium data as they were commonly used by most of the researchers. The Langmuir adsorption isotherm model is based on the assumption that monolayer coverage of lead onto a homogeneous activated carbon surface and Freundlich isotherm is based on the adsorption on heterogenous surface. The results obtained were summarized in Table 1. 
Table 1: Langmuir and Freundlich model constant and correlation coefficient R2 for adsorption of lead onto jackfruit peel activated carbon and commercial activated carbon

\begin{tabular}{|c|c|c|c|c|c|c|}
\hline \multirow{2}{*}{$\begin{array}{c}\text { Activated } \\
\text { carbon }\end{array}$} & \multicolumn{5}{|c|}{ Isotherm } \\
\cline { 2 - 7 } & $\mathrm{Q}_{\mathrm{o}}(\mathrm{mg} / \mathrm{g})$ & $\mathrm{b}(\mathrm{L} / \mathrm{mg})$ & $\mathrm{R}^{2}$ & $\mathrm{~K}_{\mathrm{F}}$ & $\mathrm{n}$ & $\mathrm{R}^{2}$ \\
\hline Jackfruit peel & 1000 & $4.63 \mathrm{E}-03$ & 0.9421 & 15.929 & 1.5835 & 0.9598 \\
\hline Commercial & 1428.57 & $1.24 \mathrm{E}-03$ & 0.9244 & 6.7174 & 1.4182 & 0.8215 \\
\hline
\end{tabular}

According to the correlation coefficient of both Langmuir and Freundlich model for jackfruit peel activated carbon, it can be noted that the adsorption of lead fit the Freundlich isotherm model better than Langmuir isotherm model where $\mathrm{R}^{2}$ equal to 0.9598 compared to Langmuir $(0.9421)$. The slope value and the RL value of the Langmuir model ranging between zero and one show that the monolayer adsorption is favorable. Whereas CAC result shows that the adsorption of lead fit the Langmuir isotherm model better than Freundlich isotherm model where $\mathrm{R}^{2}$ equal to 0.9244 . It implied that lead adsorption result is monolayer coverage by attaching to energetically homogeneous sites, which means the occurrence of a single site mechanism.

Kinetics of adsorption. The kinetics sorption describes the solute uptake rate, which in turn governs the residence time of sorption reaction. It is one of the important characteristics in defining the efficiency of sorption. In order to determine whether the adsorption kinetics of lead metal is a chemical or physical sorption, the pseudo first order and pseudo second order model were applied to study the kinetics of the adsorption process. The results were summarized in Table 2.

Table 2: Kinetic parameter estimated by Pseudo first order and Pseudo second order for jackfruit peel activated carbon and commercial activated carbon

\begin{tabular}{|c|c|c|c|c|c|c|c|}
\hline \multirow{2}{*}{$\begin{array}{c}\text { Amount } \\
\text { of dosage } \\
(\mathrm{g})\end{array}$} & \multirow{2}{*}{$\begin{array}{c}\text { qeexp } \\
(\mathrm{mg} / \mathrm{g})\end{array}$} & \multicolumn{7}{|c|}{ Pseudo-first order } & \multicolumn{3}{c|}{ Pseudo-second-order } \\
\cline { 3 - 8 } & & $\mathrm{K}_{1}(\mathrm{~min})$ & $\mathrm{R}^{2}$ & $\begin{array}{c}\mathrm{q}_{\mathrm{e} \mathrm{cal}} \\
(\mathrm{mg} / \mathrm{g})\end{array}$ & $\begin{array}{c}\mathrm{K}_{2} \times 10^{-5} \\
(\mathrm{~min})\end{array}$ & $\mathrm{R}^{2}$ & $\begin{array}{c}\text { qe cal } \\
(\mathrm{mg} / \mathrm{g})\end{array}$ \\
\hline \multicolumn{7}{|c|}{ Jackfruit peel activated carbon } \\
\hline 0.5 & 1194.80 & 0.0051 & 0.8991 & 655.239 & 0.373 & 0.9996 & 1250.00 \\
\hline \multicolumn{7}{|c|}{ Commercial activated carbon } \\
\hline 1.0 & 717.20 & 0.0035 & 0.9850 & 260.495 & 5.370 & 0.9992 & 714.286 \\
\hline
\end{tabular}

Based on the result in Table 2, the adsorption of lead metal onto JPAC and CAC fitted well with pseudo second order with the high correlation coefficient value of $\mathrm{R}^{2}$ equal to 0.9996 (for JPAC) and $\mathrm{R}^{2}$ equal to 0.9992 (for $\mathrm{CAC}$ ). This implies that the adsorption represent a chemisorption process, where the process involves the formation of covalent bond through the sharing or exchange of electron between lead metal and JPAC or CAC).

\section{Conclusion}

The results of this study indicate that JPAC can be considered as an alternative to CAC. Even though in this study the performance of JPAC is not as good as CAC, it still can be improved by further study on the production of the JPAC especially on the activation time, temperature and the 
ratio of activating agent used. The amount of lead adsorbed increases with the increase of contact time, adsorbent dosage and initial lead concentration (with excessive amount of adsorbent). Based on the experimental data, JPAC correlated reasonably well with Freundlich isotherm whereas Langmuir isotherm well fitted with the equilibrium data for adsorption of CAC. Two simplified kinetic models, pseudo-first order and pseudo-second order were tested to investigate the adsorption mechanism. The experimental data fitted very well the pseudo second order in kinetic model for both activated carbon where the adsorption controlled by chemisorptions.

\section{Acknowledgement}

This project is funded by grant OSAKA RESEARCH and supported by Universiti Malaysia Sarawak (UNIMAS).

\section{References}

[1] Ponangi S., Shyam R. A., and Joshi S. G., (2000) Trace pollution in drinking water, Journal Indian Assoc. Environment Manage, 27 16-24.

[2] Manahan S., (1984) Environmental Chemistry, Book/colei California, USA

[3] Bingau P., Lonsdale H., and Pinho M, (1986). Synthetic membranes: Science, Engineering and Application, NATO ASI Series C: Mathematical and Physical Science, vol 181, publishing Company, Dordrecht. pp 221-230.

[4] Kiffs R. J., (1987) General inorganic effluents, in: D Barnes, C. F. Forster, S. E. Hrudey (Eds.), Surveys in Industrial Wastewater Treatment - Manufacturing and Chemical Industries, vol. 3, Longman, New York, NY, (Chapter 4).

[5] Daifullah, A., Girgis, B. and Gad, H. (2004) A study of the factors affecting the removal of humic acid by activated carbon prepared from biomass material. Colloids and Surfaces A: Physicochemical and Engineering Aspects, 235, 1-10.

[6] Ulmanu, M., Marañón, E., Fernández, Y., Castrillón, L., Anger, I., \& Dumitriu, D. (2003). Removal of copper and cadmium ions from diluted aqueous solutions by low cost and waste material adsorbents. Water, Air, and Soil Pollution,142(1-4), 357-373.

[7] Ministry of Agricultural and Agro-Based Industry Malaysia (MAAIM), 2011. Available from: http://www.moa.gov.my/c/document_library/ Accessed on 10 August 2011.

[8] Fytianos K, Voudrias E, Kokkalis E. (2000). Sorption-desorption behavior of 2,4dichlorophenol by marine sediments. Chemosphere, 40(1): 3-6. 